\title{
Effect of Oxalate Precursor Formation Temperature on Magnetic Properties of NiCuZn Ferrites
}

\author{
Neelam S. Shinde ${ }^{1 *}$, Sujata S. Khot ${ }^{1}$, Bhimrao P. Ladgaonkar ${ }^{2}$, Bharat B. Kale ${ }^{3}$, Sanjay Apte ${ }^{3}$, Prasad \\ M. Tamhankar ${ }^{4}$, Shrikant C. Watawe ${ }^{4}$ \\ ${ }^{1}$ Dr.Datar Science, Dr.Behere Arts and Shri. Pilukaka Joshi Commerce (D.B.J.) College, Chiplun, Maharashtra, India; ${ }^{2}$ Shankarrao \\ Mohite Mahavidhayalaya, Akluj, Solapur, Maharashtra, India; ${ }^{3}$ Center for Materials for Electronic Technology, Pashan, Pune, India; \\ ${ }^{4}$ Lokmanya Tilak Institute of Postgraduate Teaching and Research, Gogate Jogalekar College, Ratnagiri, Maharashtra, India. \\ Email: *neelamshinde1976@gmail.com
}

Received January $1^{\text {st }}, 2011$; revised March $10^{\text {th }}, 2011$; accepted June $13^{\text {th }}, 2011$.

\begin{abstract}
$\mathrm{Ni}-\mathrm{Cu}$-Zn ferrites with general formula $\mathrm{Ni}_{0.5} \mathrm{Zn}_{0.5-\mathrm{x} / 2} \mathrm{Cu}_{\mathrm{x} / 2} \mathrm{Fe}_{2} \mathrm{O}_{4}$ (with $\mathrm{x}=0.3,0.4,0.5$ and 0.6) have been synthesized using oxalate precursor method with different precursor reaction temperatures in the range $10^{\circ} \mathrm{C}$ to $70^{\circ} \mathrm{C}$. The Curie temperatures obtained using $A C$ susceptibility measurements are found to be in the range $150^{\circ} \mathrm{C}$ to $350^{\circ} \mathrm{C}$, the measurements also show single domain structure for all the samples except few compositions obtained at $35^{\circ} \mathrm{C}$ precursor reaction temperature, show a multi-domain behaviour. The saturation magnetization is found to be in the range 20 to $51 \mathrm{emu} / \mathrm{gm}$, while the magnetic moment is found to be in the range 0.63 to $1.5 \mu \mathrm{B}$. The hysteresis losses were found to be maximum for the samples obtained at precursor reaction temperature of $35^{\circ} \mathrm{C}$. The grain size is found to be in the range 0.4 to $2.0 \mu \mathrm{m}$.
\end{abstract}

Keywords: Magnetic Materials, Temperature of Chemical Reaction, Magnetic Susceptibility, Curie Temperature

\section{Introduction}

NiZn ferrites have been used in the high frequency applications and also multilayer chip conductor with silver as a suitable material for inner conductor, however cofiring silver with the NiZn ferrites at higher temperature of $1250^{\circ} \mathrm{C}$ is unsuitable as the melting point of silver is $961^{\circ} \mathrm{C}[1,2] . \mathrm{Cu}^{2+}$ can be introduced to reduce the sintering temperature and at the same time enhance sintering process $[3,4]$. Ni-Cu-Zn Ferrites having oxygen deficiency have been reported to be useful materials in $\mathrm{CO}_{2}$ decomposition in reducing green house effect with $100 \%$ efficiency [5]. The synthesis of ferrites can be carried out using different methods but the low temperature synthesis and molecular level mixing is reported to be useful in obtaining desired magnetic properties and the reaction kinematics in a chemical process dependent on the temperature at which it is carried out [6]. A combination of lower reaction temperature followed by calcination at suitable elevated temperature for the solid state reaction could be useful for synthesizing the ferrites with required parameters.
Various preparation techniques such as sol gel auto combustion [7], microwave assisted combustion synthesis [8,9], soft chemical method [10-14], combustion synthesis [15] have been used to synthesize ferrites. In the present communication, efforts have been made to synthesize $\mathrm{Ni}-\mathrm{Cu}-\mathrm{Zn}$ ferrites in two steps, involving oxalate co-precipitation at three different reaction temperatures [16], followed by calcination at $600^{\circ} \mathrm{C}$ for the completion of the solid state reaction. The choice of calcinations temperature has been based on the fact that ferrous oxalate gets converted into ferrous oxide at $400^{\circ} \mathrm{C}$ [17] while the ferrite formation is reported to take place at around $600^{\circ} \mathrm{C}[18,20]$. It has also been reported that there is exothermic peak around $620^{\circ} \mathrm{C}$ due to crystallization [21,22].

\section{Experimental}

$\mathrm{Ni}-\mathrm{Cu}-\mathrm{Zn}$ ferrites with general formula $\mathrm{Ni}_{0.5} \mathrm{Zn}_{0.5-\mathrm{x} / 2} \mathrm{Cu}_{\mathrm{x} / 2^{-}}$ $\mathrm{Fe}_{2} \mathrm{O}_{4}$ (with $x=0.3,0.4,0.5$ and 0.6 ) have been synthesized using AR grade metal sulphates as starting material. The stoichiometric proportions of metal sulphates were 
added to $200 \mathrm{ml}$ distilled water. The temperature of chemical reaction was maintained at three different values i.e. $10^{\circ} \mathrm{C}, 35^{\circ} \mathrm{C}$ and $70^{\circ} \mathrm{C}$, using thermally controlled water bath. The chemicals were also maintained at the three temperatures before the chemical reaction was carried out. The reaction temperatures were chosen considering the room temperature of the work place during summer. The summer room temperature is in the range of $35^{\circ} \mathrm{C}$ which could be easily maintained. The other two temperatures were chosen which have the variation of more than $25^{\circ} \mathrm{C}$ on either side of the room temperature.

Ammonium oxalate was added drop by drop in the flask containing the metal sulphates up to the completion of the chemical reaction. Barium chloride test was used to confirm the completion of chemical reaction. The filtrate was filtered and washed with distilled water and dried using electric lamp. Oxalates in precursor act like a combustion agent which helps in lowering the calcination temperature. Therefore the solid state reaction to obtain the ferrites was carried out in muffle furnace at optimized temperature of $600^{\circ} \mathrm{C}$ for $6 \mathrm{Hrs}$ for all samples irrespective of the oxalate reaction temperature. X-ray diffractograms were recorded using Philips PW 1710 powder diffractometer by scanning in the range $20^{\circ} \mathrm{C}$ to $80^{\circ} \mathrm{C}$. AC susceptibility measurements were carried out using Helmholtz double coil setup operated at $263 \mathrm{~Hz}$ with a constant field of 7 Oe. Hysteresis measurements were done using the hysteresis loop tracer. SEM micrographs were taken on JEOL-JEM-6360 microscopes to obtain the grain size of the samples.

\section{Results and Discussions}

The XRD patterns indicate the single phase cubic structure for all the samples. The effects of reaction temperatures on the position of most intense (311) peak in the diffraction pattern are shown in Figures 1 2, 3 and 4. The peak is found to shift towards smaller angle for reaction temperature $35^{\circ} \mathrm{C}$ for all the compositions, while the peak intensities are found to be maximum for reaction temperature of $70^{\circ} \mathrm{C}$ for $x=0.3$ and 0.4 while for $x=0.5$ and 0.6 the maximum intensity is observed at reaction temperature of $10^{\circ} \mathrm{C}$. The reaction temperatures show their effects in position as well as the intensity of the (311) peak. The variation in peak intensities and sharpness with reaction temperature has been reported by Qu et.al [23]. They have also reported the increase in grain size, lattice constant and Ms with reaction temperature.

Figures 5, 6 and 7 depict the variation of normalized AC susceptibility with temperature for all the compositions at different reaction temperatures. All the samples at reaction temperature of $10^{\circ} \mathrm{C}$ and $70^{\circ} \mathrm{C}$ show SD behaviour while two compositions at $35^{\circ} \mathrm{C}$ show $\mathrm{MD}$ be haviour. The magnetic properties are structure sensitive and the grain size plays a significant role. The Curie temperature, at which the normalized susceptibility drops off sharply, shows a variation with reaction temperature. For synthesis at temperature of $10^{\circ} \mathrm{C}$ the Curie temperature is found to be in the range 120 to $220^{\circ} \mathrm{C}$. For the reaction temperature of $35^{\circ} \mathrm{C}$, it is in the range of 220 to $290^{\circ} \mathrm{C}$ while for the reaction temperature of $70^{\circ} \mathrm{C}$ it is in the range 180 to $260^{\circ} \mathrm{C}$. The value of Curie temperature is found to be minimum for $x=0.4$ for all the reaction temperatures while its value is maximum for the samples synthesized at $35^{\circ} \mathrm{C}$ for all the compositions. The Curie temperature depends mainly on A-B interaction which is determined by the cations present in the sample. The substitution of $\mathrm{Cu}^{2+}$ ions in place of $\mathrm{Zn}^{2+}$, changes the magnetic moment on both the sites whereby the A-B interaction changes. The Curie temperature is sensitive to the calcination temperature but in the present case even though the calcination temperature is same for all the samples, there is variation in Curie temperature with composition as well as the chemical reaction temperature indicating the effect of chemical reaction temprature even after calcination.

Figure 8 depicts the hysteresis loops for all the samples studied. The values of saturation magnetization and magnetic moment shown in Table $\mathbf{1}$ are found to increase with increase in reaction temperature up to $x=0.4$ while for $x>0.4$ the maximum value is observed for reaction temperature of $35^{\circ} \mathrm{C}$. The retentivity for all the samples is found to increase with reaction temperatures. Shrotri et al. [10 ] have reported decrease in Ms with increase in $\mathrm{Cu}^{2+}$ content for ferrites with similar composition synthesized at $80^{\circ} \mathrm{C}$. The substitution of $\mathrm{Cu}^{2+}$ ions is reported to show canting behaviour for higher concentration $[24,11,19]$ which is also observed in the present case. The variation in magnetization is also found to depend upon the reaction temperature, where it is found to show larger values for reaction temperature of $35^{\circ} \mathrm{C}$ which happens to be the room temperature.

The SEM micrographs for the samples with $x=0.4$ and $x=0.5$ at the three reaction temperatures studied are shown in Figures 9 and 10. Maximum grain size is obtained for $x=0.4$ which is in the range 0.6 to $1.95 \mu \mathrm{m}$ for the samples studied. The grain size is found to increase with reaction temperature indicating the effect of reaction history on the grain size. The grain size is found to be maximum for the reaction temperature of $35^{\circ} \mathrm{C}$ which happens to be the room temperature.

\section{Conclusions}

The oxalates co-precipitation reactions were carried out at $10^{\circ} \mathrm{C}, 35^{\circ} \mathrm{C}$ and $70^{\circ} \mathrm{C}$ temperatures while the solid state reaction was carried out at $600^{\circ} \mathrm{C}$ for all the samples, show variation with composition as well as reaction temperature in the structural as well as magnetic proper- 

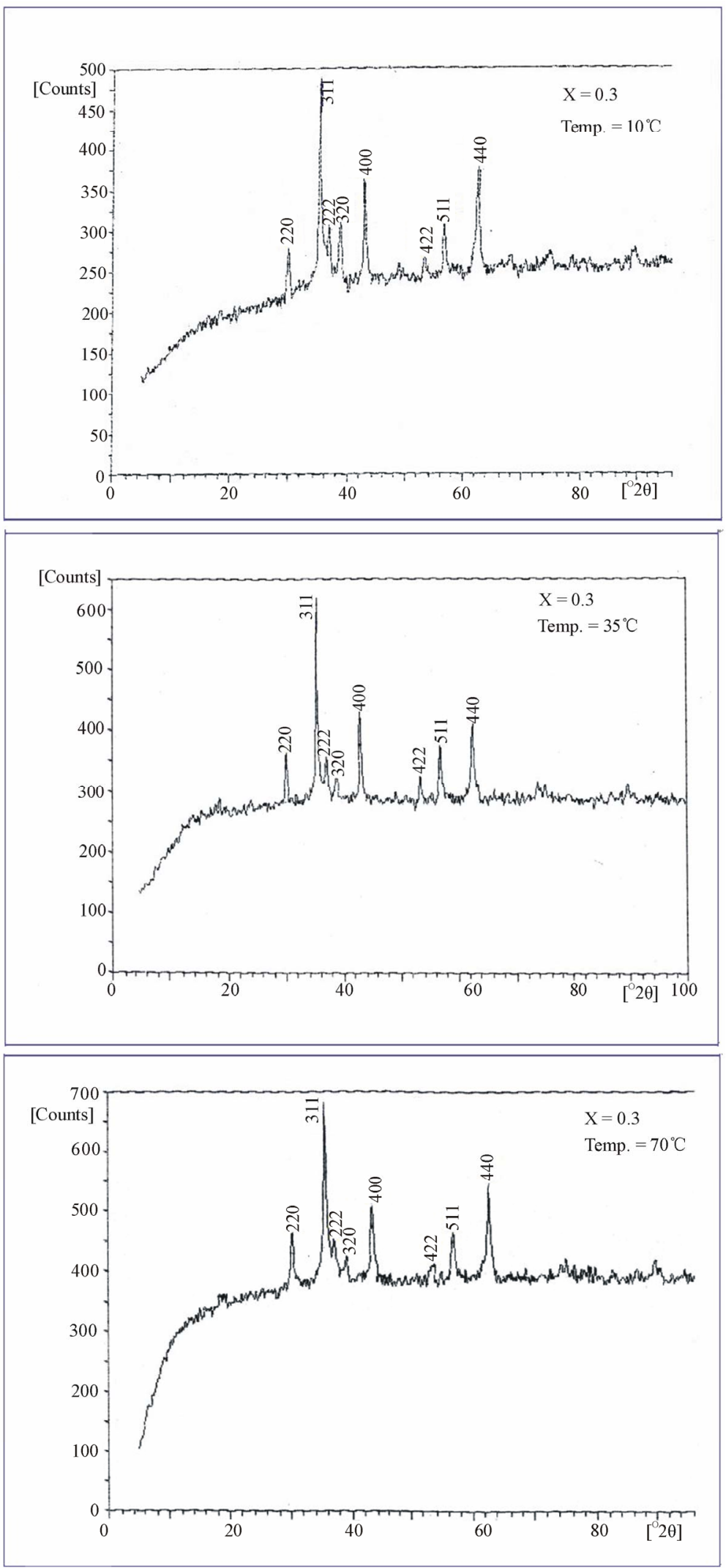

Figure 1. Variation of most intense (311) peak with temperature of chemical reaction for the composition $\mathrm{x}=\mathbf{0 . 3}$. 

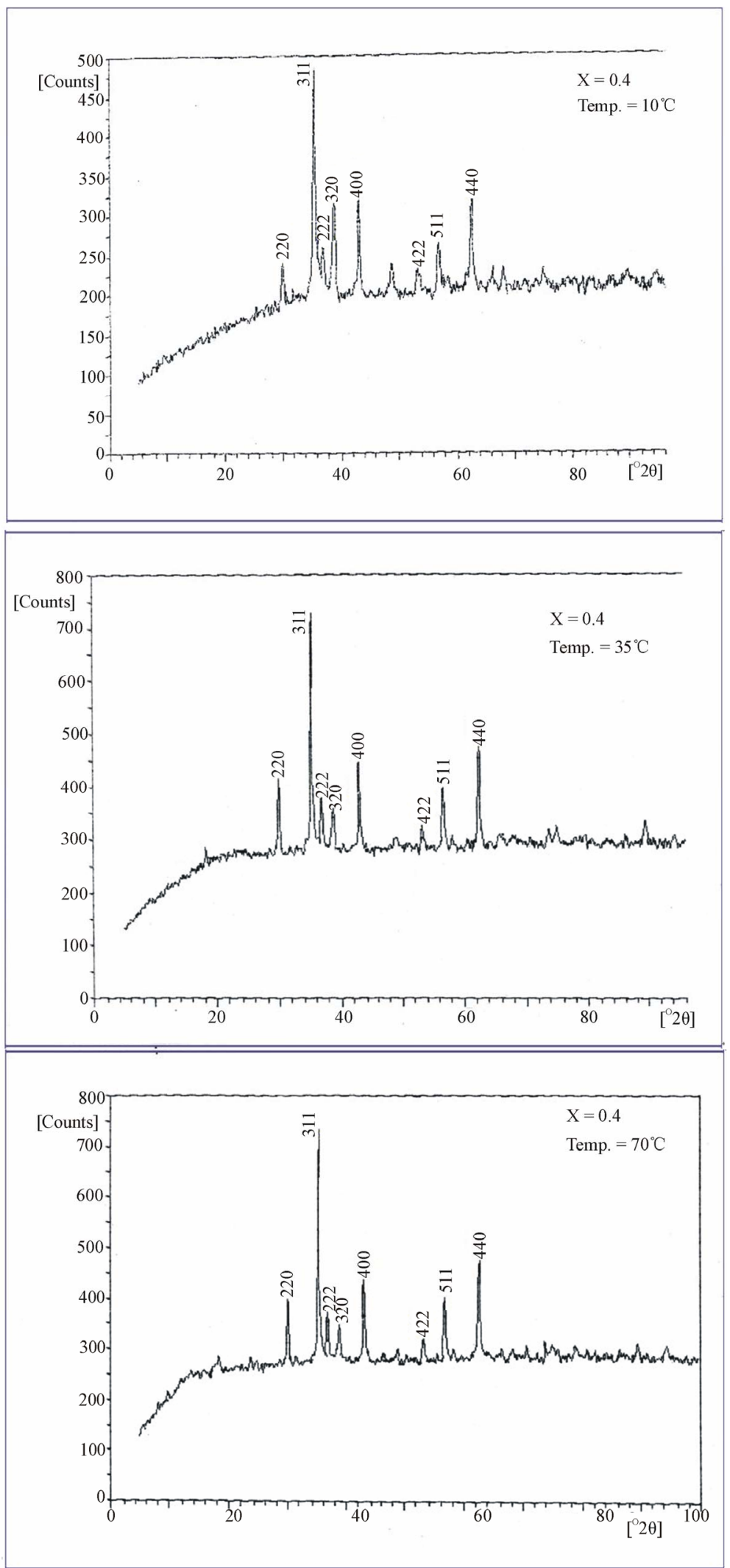

Figure 2. Variation of most intense (311) peak with temperature of chemical reaction for the composition $\mathrm{x}=\mathbf{0 . 4}$. 

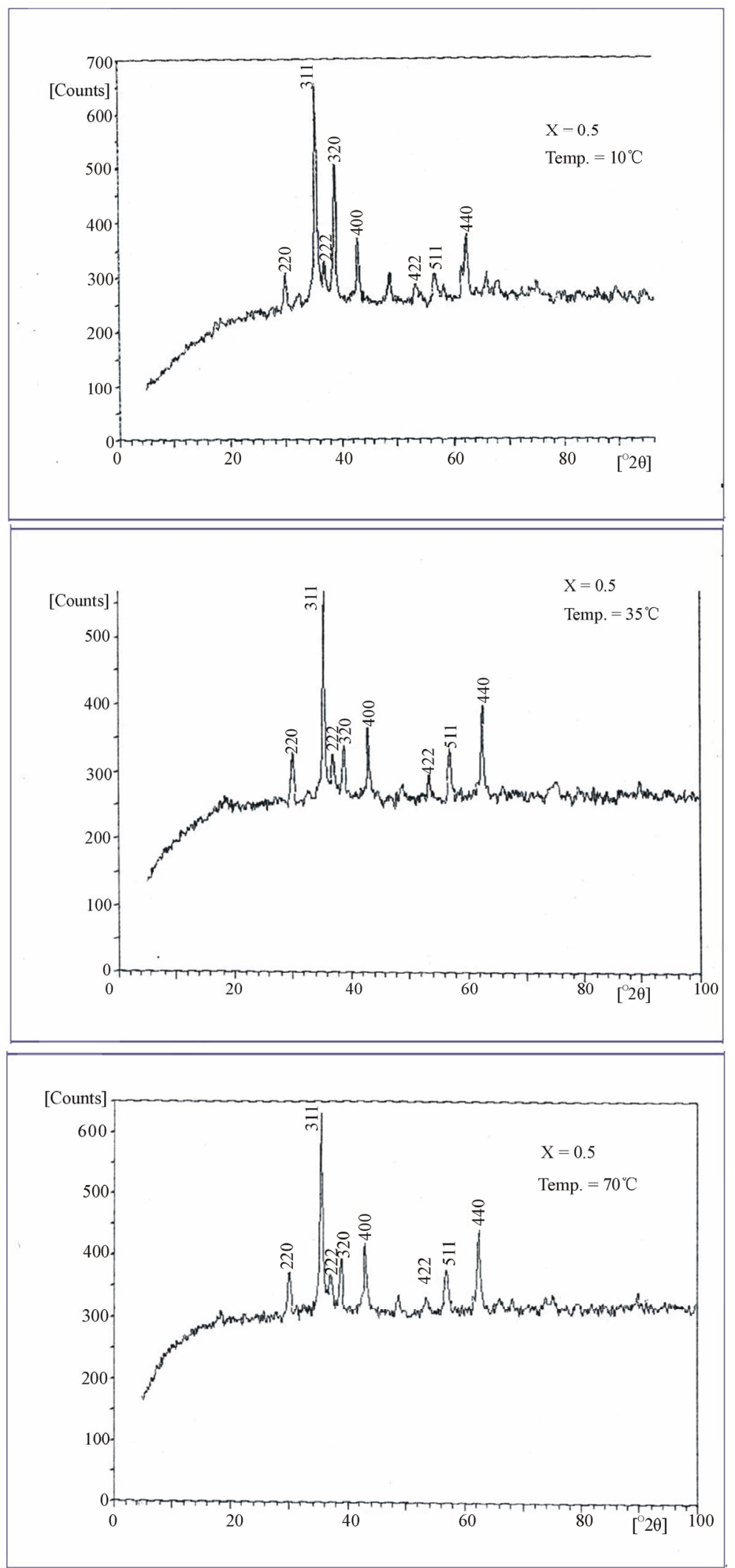

Figure 3. Variation of most intense (311) peak with temperature of chemical reaction for the composition $\mathrm{x}=\mathbf{0 . 5}$. 

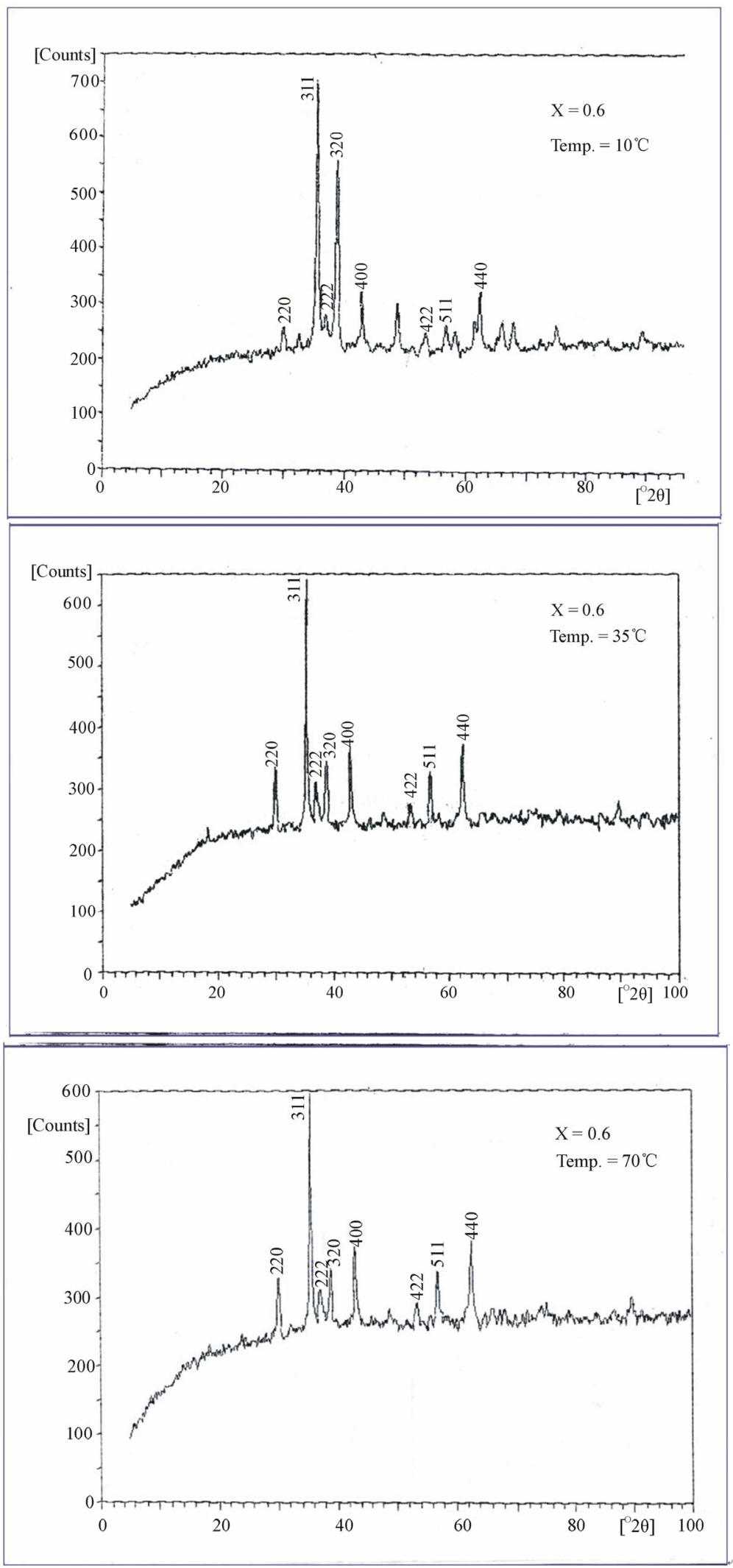

Figure 4. Variation of most intense (311) peak with temperature of chemical reaction for the composition $\mathrm{x}=\mathbf{0 . 6}$. 


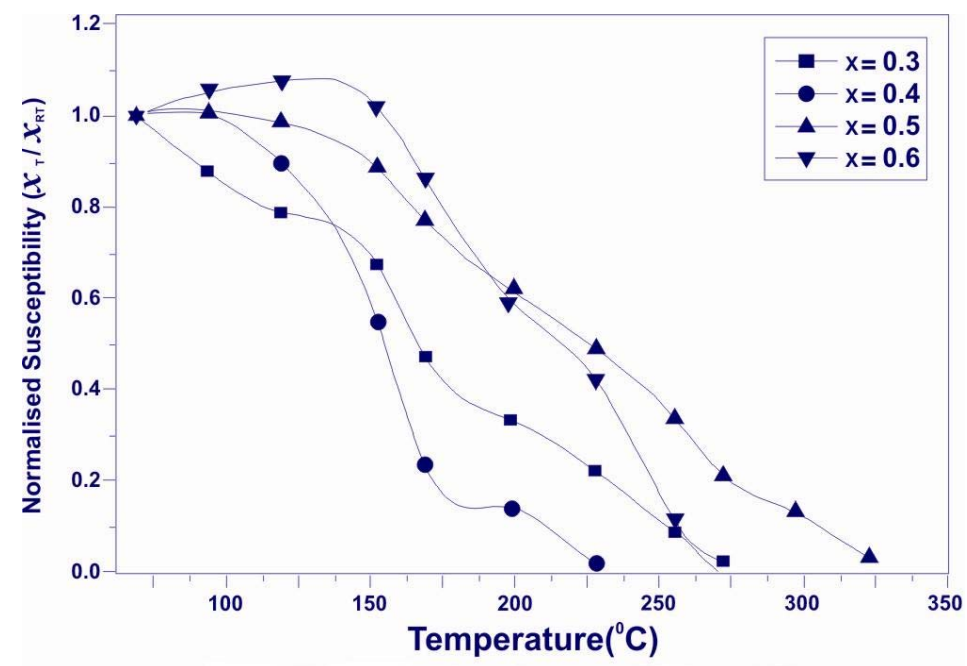

Figure 5. Variation of normalized AC susceptibility for compositions $x=0.3, x=0.4, x=0.5$ and $x=0.6$ at reaction temperature $10^{\circ} \mathrm{C}$.

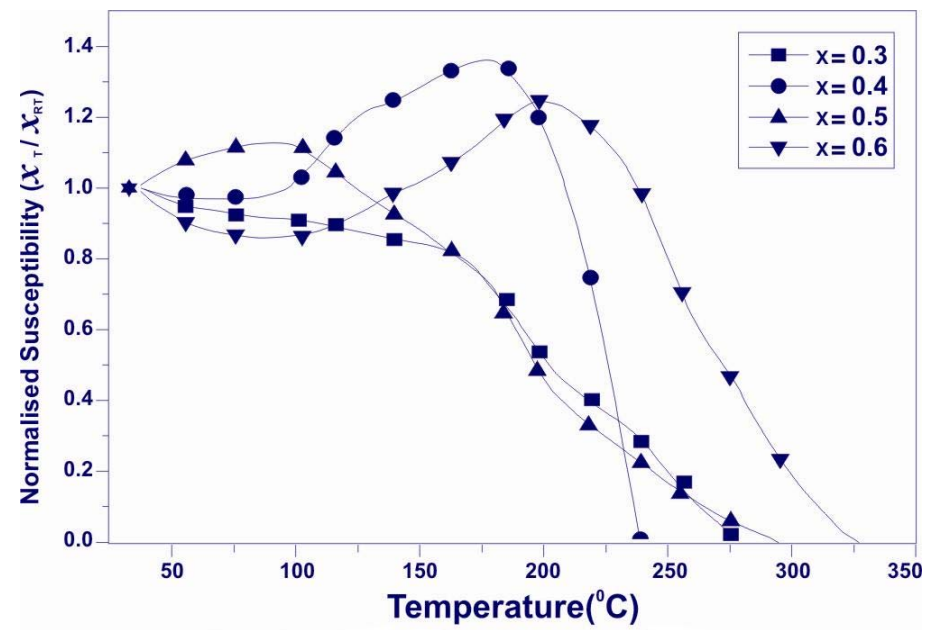

Figure 6. Variation of normalized AC susceptibility for compositions $x=0.3, x=0.4, x=0.5$ and $x=0.6$ at reaction temperature $35^{\circ} \mathrm{C}$.

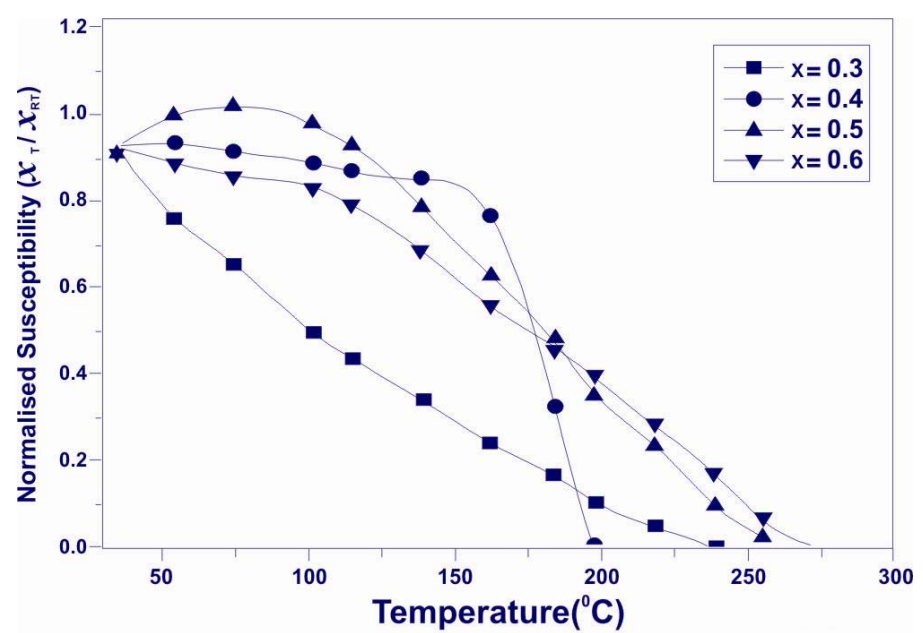

Figure 7. Variation of normalized AC susceptibility for compositions $x=0.3, x=0.4, x=0.5$ and $x=0.6$ at reaction temperature $70^{\circ} \mathrm{C}$. 


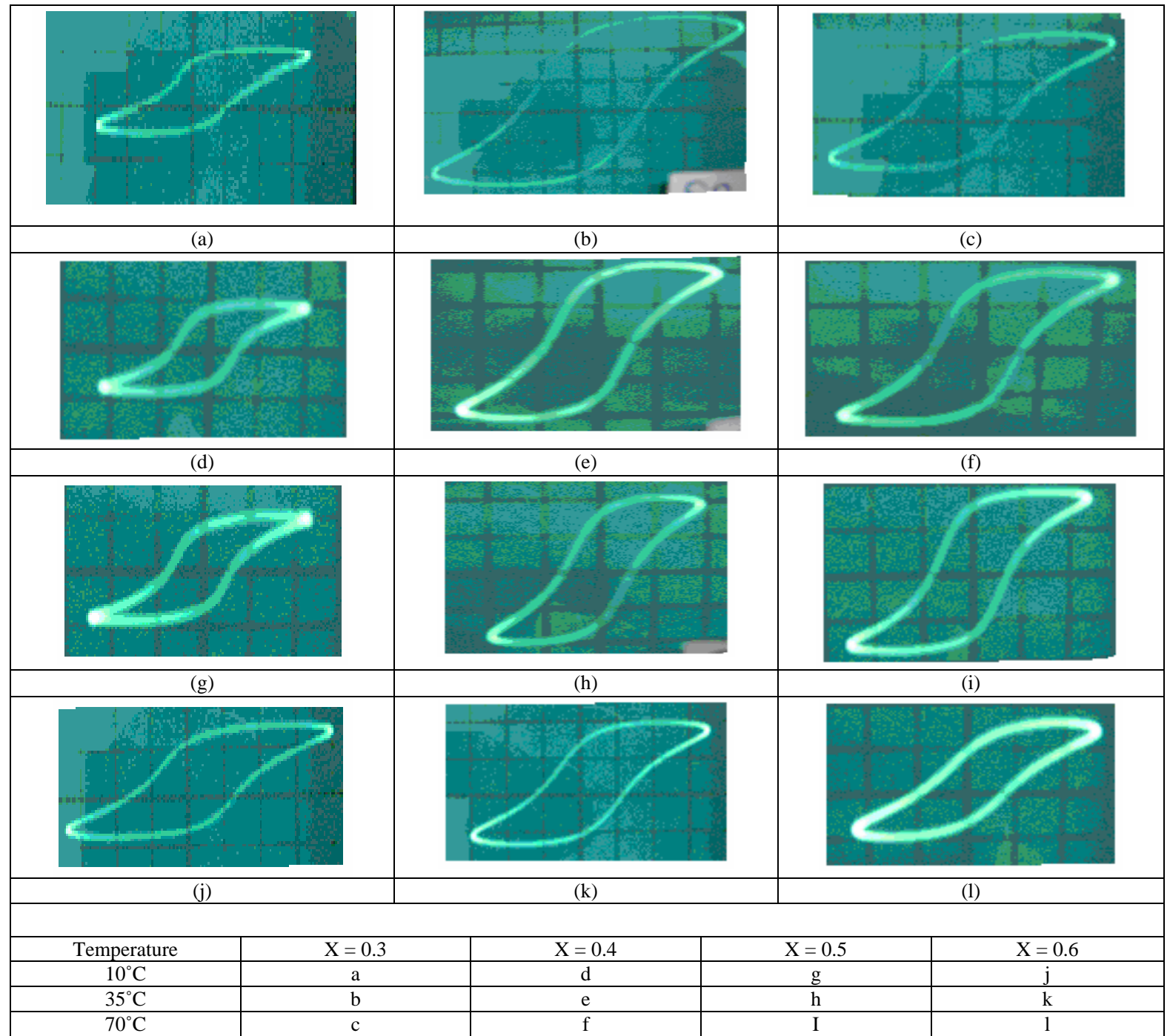

Figure 8. The hysteresis loops for compositions $x=0.3, x=0.4, x=0.5$ and $x=0.6$ at reaction temperatures $10^{\circ} \mathrm{C}, 35^{\circ} \mathrm{C}$ and $70^{\circ} \mathrm{C}$.

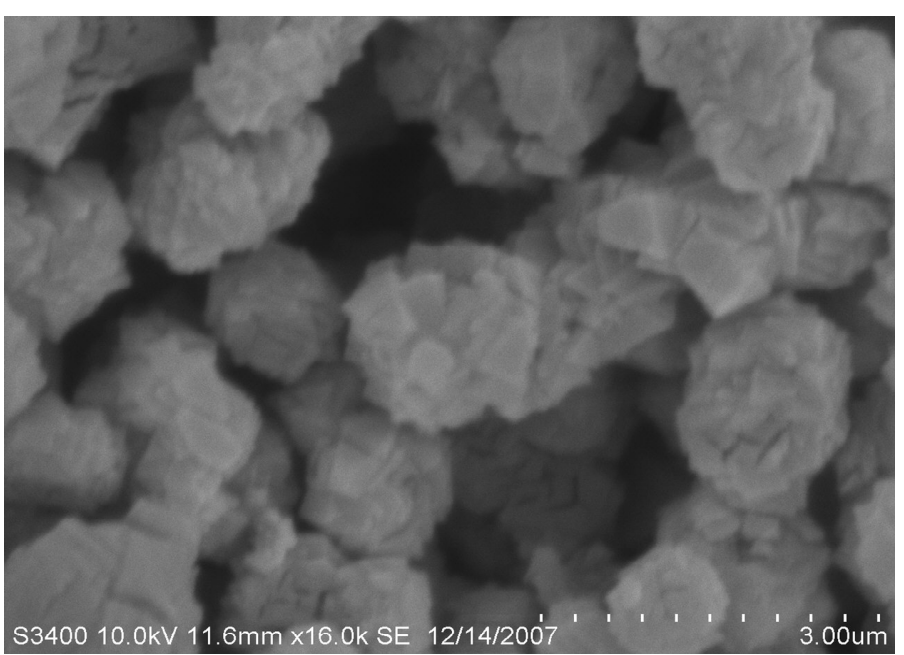

(a) 


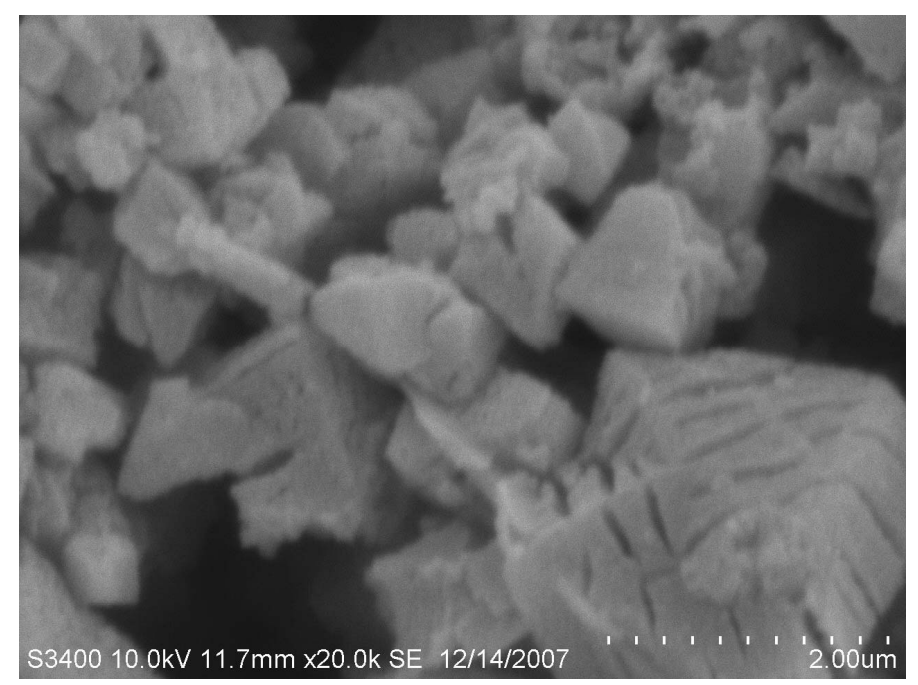

(b)

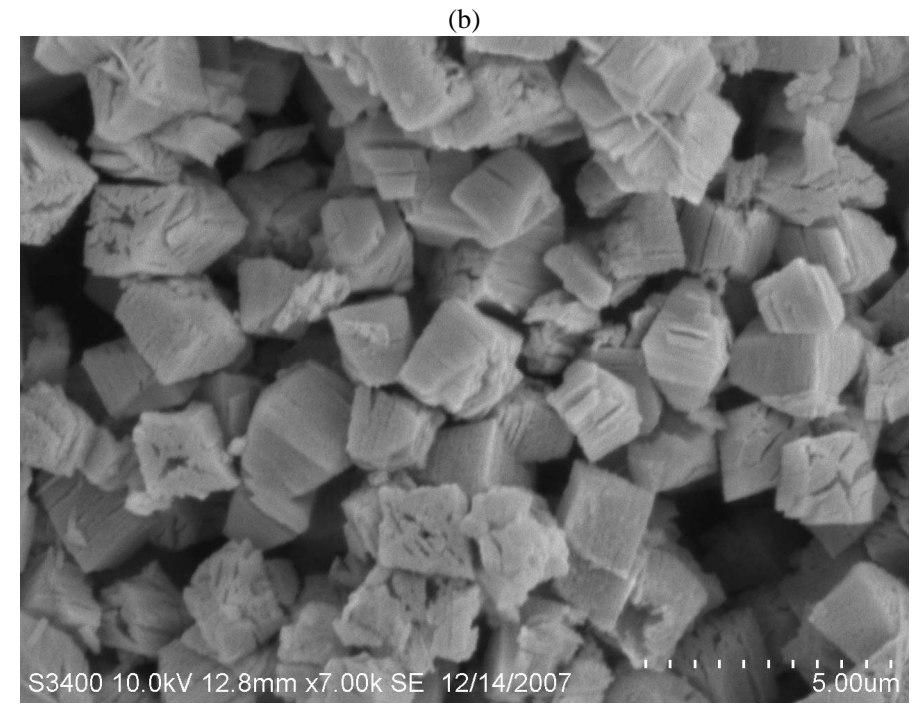

(c)

Figure 9. SEM micrographs for $x=0.4$ at reaction temperatures (a) $10^{\circ} \mathrm{C}$, (b) $35^{\circ} \mathrm{C}$ and (c) $70^{\circ} \mathrm{C}$.

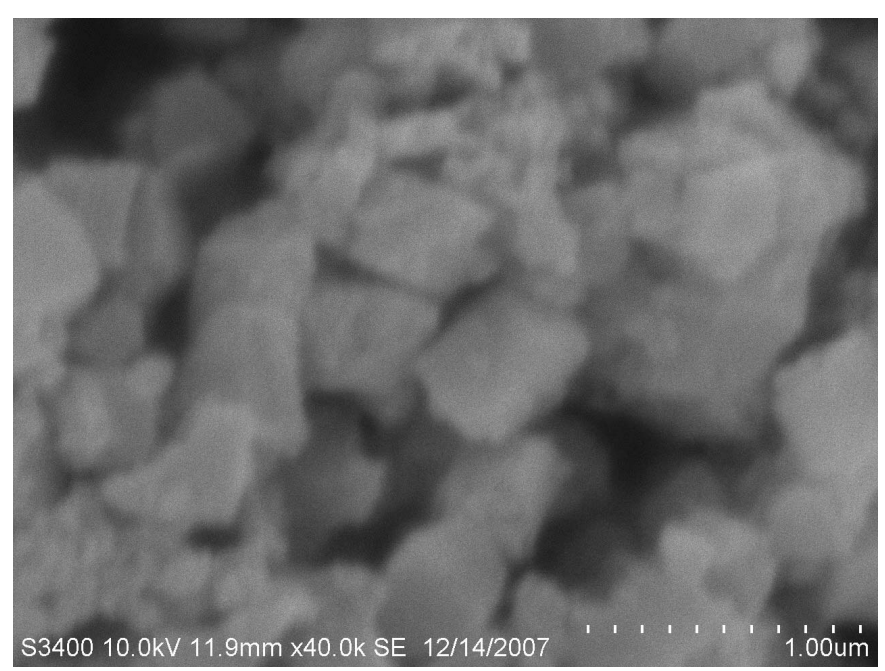

(a) 


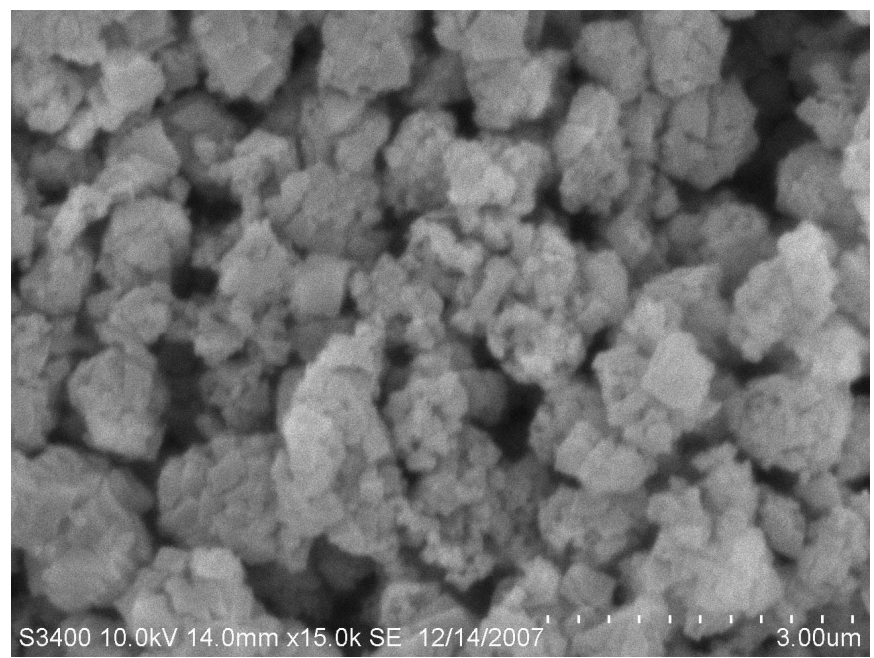

(b)

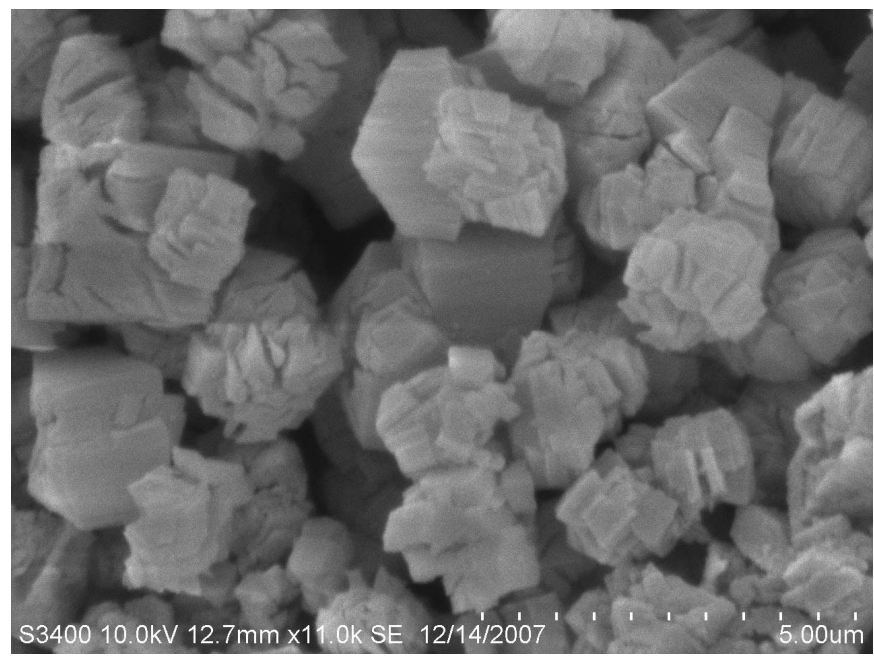

(c)

Figure 10. SEM micrographs for $x=0.5$ at reaction temperatures (a) $10^{\circ} \mathrm{C}$, (b) $35^{\circ} \mathrm{C}$ and (c) $70^{\circ} \mathrm{C}$.

Table 1. Variation of magnetic properties with composition and chemical reaction temperature.

\begin{tabular}{|c|c|c|c|c|c|c|}
\hline $\begin{array}{c}\text { Temperature } \\
\text { of reaction }\left({ }^{\circ} \mathrm{C}\right)\end{array}$ & $\begin{array}{c}\text { Composition parameter } \\
x x\end{array}$ & Ms (emu/gm) & $\begin{array}{c}\text { Magnetic moment } \\
\left(\mu_{\mathrm{B}}\right)\end{array}$ & $\begin{array}{l}\text { Retentivity } \\
\text { (emu/gm) }\end{array}$ & Curie Temperature $\left({ }^{\circ} \mathrm{C}\right)$ & $\begin{array}{l}\text { Grain size } \\
\quad(\mu \mathrm{m})\end{array}$ \\
\hline \multirow{4}{*}{10} & 0.3 & 32.06 & 1.00 & 20.04 & 180 & - \\
\hline & 0.4 & 20.25 & 0.63 & 14.17 & 120 & 0.6 \\
\hline & 0.5 & 28.57 & 0.89 & 22.85 & 220 & 0.4 \\
\hline & 0.6 & 28.51 & 0.67 & 17.59 & 175 & - \\
\hline \multirow{4}{*}{35} & 0.3 & 42.97 & 1.33 & 35.29 & 260 & - \\
\hline & 0.4 & 50.44 & 1.57 & 38.95 & 220 & 1.0 \\
\hline & 0.5 & 46.18 & 1.43 & 32.98 & 260 & 0.6 \\
\hline & 0.6 & 38.17 & 1.21 & 27.43 & 290 & - \\
\hline \multirow{4}{*}{70} & 0.3 & 47.02 & 1.46 & 37.12 & 220 & - \\
\hline & 0.4 & 51.05 & 1.58 & 39.03 & 180 & 1.95 \\
\hline & 0.5 & 46.07 & 1.43 & 35.83 & 250 & 1.5 \\
\hline & 0.6 & 37.09 & 1.15 & 28.53 & 260 & - \\
\hline
\end{tabular}


ties, indicating the effect of chemical reaction history on the properties of ferrites. The temperature of chemical reaction may conveniently be used to synthesize ferrites with suitable properties.

\section{REFERENCES}

[1] Wei-Chih Hsu, S. C. Chen, P. C. Kuo, C. T. Lie and W. S. Tsai, "Preparation of NiCuZn Ferrite Nanoparticles from Chemical Co-Precipitation Method and the Magnetic Properties after Sintering," Material Science and Engineering: B, Vol. 111, August 2004, pp. 142-149.

[2] J. Dong-yin and B. Pei, "Transactions of Nonferrous Metals,” Society of China, Vol. 16, 2006, pp. 67-70.

[3] H. Su, H. W. Zhang, X. L. Tang and X. Y. Xiang, "High Permeability and High Curie Temperature NiCuZn Ferrite,” Journal of Magnetism and Magnetic Materials, Vol. 283, No. 3-4, December 2004, pp.157-163. doi:10.1016/j.jmmm.2004.05.017

[4] M. M. Haque, M. Huq and M. A. Hakim, "Influence of $\mathrm{CuO}$ and Sintering Temperature on the Microstructure And Magnetic Properties of Mg-Cu-Zn ferrites,” Journal of Magnetism and Magnetic Materials, Vol. 320, No. 21, November 2008, pp. 2792-2799. doi:10.1016/j.jmmm.2008.06.017

[5] L. J. Ma, L. S. Chen and S. Y. Chen, "Study on the Characteristics and Activity of Ni-Cu-Zn Ferrite for Decomposition of $\mathrm{CO}_{2}$," Materials, Chemistry and Physics, Vol. 114, No, 2-3, April 2009, pp. 692-696. doi:10.1016/j.matchemphys.2008.10.050

[6] Mathew George, Asha Mary John, Swapna S. Nair, P. A. Joy and M. R. Anantharaman, "Finite Size Effects on the Structural and Magnetic Properties of Sol-Gel Synthesized $\mathrm{NiFe}_{2} \mathrm{O}_{4}$ Powders," Journal of Magnetism and Magnetic Materials, Vol. 302, No. 1, July 2006, pp. 190-195. doi:10.1016/j.jmmm.2005.08.029

[7] Zhenxing Yue, Ji Zhou, Longtu Li, Hongguo Zhang and Zhilun Gui, "Synthesis of Nanocrystalline NiCuZn ferrite Powders by Sol-Gel Auto-Combustion Method,” Journal of Magnetism and Magnetic Materials, Vol. 208, No. 1-2, January 2000, pp. 55-60. doi:10.1016/S0304-8853(99)00566-1

[8] M. Yan and J. Hu, "Microwave Sintering of High Permeability $\left(\mathrm{Ni}_{0.20} \mathrm{Zn}_{0.60} \mathrm{Cu}_{0.20}\right) \mathrm{Fe}_{1.98} \mathrm{O}_{4}$ Ferrite at Low Sintering Temperatures," Journal of Magnetism and Magnetic Materials, Vol. 305, No. 1, October 2006, pp. 171176. doi:10.1016/j.jmmm.2005.12.008

[9] S. C. Watawe, S. Keluskar, Gonbare and R. B. Tangsali, "Preparation and Magnetic Properties of Cadmium Substituted Lithium Ferrite Using Microwave Induced Combustion,” Thin Solid Films, Vol. 505, No. 1-2, May 2006, pp. 168-172. doi:10.1016/j.tsf.2005.10.032s

[10] J. J. Shrotri, S. D. Kulkarni, C. E. Deshpande, A. Mitra, S. R. Sainkar, P. S. A. Kumar and S. K. Date, "Effect of $\mathrm{Cu}$ Substitution on the Magnetic and Electrical Properties of Ni-Zn Ferrite Synthesized by Soft Chemical," Materials Chemistry and Physics, Vol. 59, No. 1, April 1999, pp.

\section{1-5. doi:10.1016/S0254-0584(99)00019-X}

[11] C. W. Kim and J. G. Koh, "A Study of Synthesis of NiCuZn Ferrite Sintering in Low Temperature by Metal Nitrates and Its Electromagnetic Property," Journal of Magnetism and Magnetic Materials, Vol. 257, No, 2-3, February 2003, pp. 355-368.

doi:10.1016/S0304-8853(02)01234-9

[12] I. Z. Rahman and T. T. Ahmed, "A Study on Cu substituted Chemically Processed Ni-Zn-Cu Ferrites,” Journal of Magnetism and Magnetic Materials, Vol. 290-291, No. 2, April 2005, pp. 1576-1579.

[13] P. S. A. Kumar, J. J. Shrotri, S. D. Kulkami, C. E. Deshpande and S. K. Date, "Low Temperature Synthesis of $\mathrm{Ni}_{0.8} \mathrm{Zn}_{0.2} \mathrm{Fe}_{2} \mathrm{O}_{4}$ Powder and Its Characterization,” Materials Letters, Vol. 27, No. 6, August 1996, pp. 293-296. doi:10.1016/0167-577X(96)00010-9

[14] S. A. Ghodake, U. R. Ghodake, S. R. Sawant, S. S. Suryavanshi and P. P. Bakare, "Magnetic Properties of NiCuZn Ferrites Synthesized by Oxalate Precursor Method," Journal of Magnetism and Magnetic Materials, Vol. 305, No. 1, October 2006, pp. 110-119.

[15] Y. Li, J. P. Zhao, J. C. Han and X. D. He, "Combustion Synthesis and Characterization of NiCuZn Ferrite Powders,” Materials Research Bulletin, Vol. 40, No. 6, June 2005, pp. 981-989. doi:10.1016/j.materresbull.2005.02.018

[16] J. L. M. de Vidales, A. Lo'pez-Delgado, E. Vila and F. A. Lo'pez, "The Effect of the Starting Solution on the Physico-Chemical Properties of Zinc Ferrite Synthesized at Low Temperature," Journal of Alloys and Compounds, Vol. 287, No. 1-2, June 1999, pp. 276-283. doi:10.1016/S0925-8388(99)00069-9

[17] X. Y. Li, G. X. Lu and S. B. Li, "Synthesis and Characterization of Fine Particle $\mathrm{ZnFe}_{2} \mathrm{O}_{4}$ Powders by a Low Temperature Method,” Journal of Alloys and Compounds, Vol. 235, No. 5, March 1996, pp. 150-155. doi:10.1016/0925-8388(95)02022-5

[18] T. Nakamura, "Low-Temperature Sintering of Ni-Zn-Cu Ferrite and Its Permeability Spectra,” Journal of Magnetism and Magnetic Materials, Vol. 168, No. 3, April 1997, pp. 285-291. doi:10.1016/S0304-8853(96)00709-3

[19] S. Modak, M. Ammar, F. Mazaleyrat, S. Das and P. K. Chakrabarti, "XRD, HRTEM and Magnetic Properties of Mixed Spinel Nanocrystalline Ni-Zn-Cu Ferrite,” Journal of Alloys and Compounds, Vol. 473, No. 1-2, April 2009, pp.15-19. doi:10.1016/j.jallcom.2008.06.020

[20] U. R. Lima, M. C. Nasar, R. S. Nasara, M. C. Rezende, J. H. Araújo and J. F. Oliveira, "Synthesis of NiCuZn Ferrite Nanoparticles and Microwave Absorption Characterization," Materials Science and Engineering B, Vol. 151, No. 3, July 2008, pp. 238-242. doi:10.1016/j.mseb.2008.06.032

[21] Y. P. Fu, C. H. Lin and C. W. Liu, "Preparation and Magnetic Properties of $\mathrm{Ni}_{0.25} \mathrm{Cu}_{0.25} \mathrm{Zn}_{0.5}$ Ferrite from Microwave-Induced Combustion," Journal of Magnetism and Magnetic Materials, Vol. 283, No. 1, November 2004, pp. 59-64. 
[22] J. Y. Hsu, W. S. KO, H. D. Shen and C. J. Chen, "Quasi Static Electromagnetic Field Problems,” IEEE Transactions on Magnetics, Vol. 30, 1994, p. 6.

[23] Y. Q. Qu, H. B. Yang, N. Yang, Y. Z. Fan and H. Y. Zhu, "The Effect of Reaction Temperature on the Particle Size, Structure and Magnetic Properties of Co-Precipitated $\mathrm{CoFe}_{2} \mathrm{O}_{4}$ Nanoparticles,” Materials Letters, Vol. 60, No.
29-30, December 2006, pp. 3548-3552. doi:10.1016/j.matlet.2006.03.055

[24] J. Slama, A. Gruskova, M. Usakova, E. Usak and R. Dosoudil, "Contribution to Analysis of Cu-Substituted NiZn Ferrites,” Journal of Magnetism and Magnetic Materials, Vol. 321, No. 19, October 2009, pp. 3346-3351. doi:10.1016/j.jmmm.2009.06.024 